\title{
O SILÊNCIO DA GRIPE ESPANHOLA NO BRASIL: uma história a ser recordada em tempos de Covid-19
} THE SILENCE OF THE SPANISH FLU IN BRAZIL: a story to remember in times of Covid-19

\author{
Pâmella Tamires Avelino de SOUSA ${ }^{1}$ \\ Universidade Federal da Paraíba | Brasil
}

\begin{abstract}
Resumo
Esta Resenha de A Bailarina da Morte: A gripe espanhola no Brasil (2020) analisa como a pesquisa desenvolvida por Lilia Moritz Schwarcz e Heloisa Murgel Starling questiona o enfrentamento da crise sanitária da influenza H1N1. As autoras narram o que aconteceu em capitais brasileiras nos anos de 1918 e 1919, quando houve, no Brasil e no mundo, uma epidemia que ficou conhecida como gripe espanhola. Vivenciando também um período de pandemia - Covid-19 -, as autoras nos propõem refletir sobre inúmeras atitudes, inclusive em relação aos métodos de pesquisa disponíveis nesse momento. Utilizando jornais como fontes e pesquisas acadêmicas, identificamos um panorama da crise enfrentada no início do século XX.

Palavras-chave

Influenza H1N1; Gripe Espanhola; Covid-19; Jornal; Pandemia.

\section{Abstract}

This review of "The ballerina of death: The Spanish flu in Brazil" (2020) - Original title: A bailarina da morte: A gripe espanhola no Brasil.- analyzes how the research developed by Lilia Moritz Schwarcz and Heloisa Murgel Starling questions the confrontation of the sanitary crisis of the H1N1 influenza. The authors narrate what happened in Brazilian capitals in the years 1918 and 1919, when there was, in Brazil and in the world, an epidemic that became known as the Spanish flu. Also experiencing a period of pandemic - Covid-19-, the authors proposes to reflect on countless attitudes, including in relation to the research methods available at that time. Using newspapers as academic sources and research, we identify a panorama of the crisis faced in the beginning of the 20th century.

Keywords

H1N1 Influenza; Spanish flu; Covid-19; News; Pandemic.
\end{abstract}

RECEBIDO EM 24 DE MARÇO DE 2021

ACEITO EM 8 DE JULHO DE 2021

\begin{abstract}
${ }^{1}$ Formação em Pedagogia pela Universidade Federal de Campina Grande (2013). Mestre em Educação pela Universidade Federal de Campina Grande (PPGEd/UFCG). Atualmente está estudando Doutorado em Educação no Centro de Educação; Programa de Pós Graduação em Educação/PPGE - Universidade Federal da Paraíba (UFPB). Bolsista do Conselho Nacional de Desenvolvimento Científico e Tecnológico/CNPq. Contato: pamellatasousa@gmail.com.
\end{abstract}

João Pessoa - Brasil | ANO 8 VOL.8 N.1 | JAN./JUN. 2021 | p. 192 a 203

Revista Latino-americana de Jornalismo | ISSN 2359-375X

Programa de Pós-Graduação em Jornalismo - UFPB

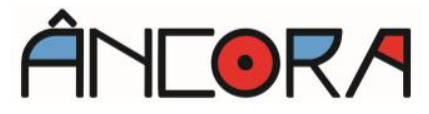




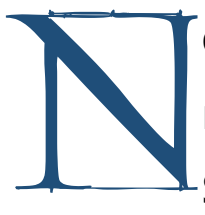
o ano de 2020, uma crise sanitária afligiu o mundo. A população receosa e seguindo as recomendações da Organização Mundial de Saúde (OMS) abandona a rotina das escolas, trabalhos, do lazer e, consequentemente, da vida social. A Covid-19 mudaria repentinamente as formas de contato, diálogo, trabalho, estudo, saúde, coletividade, economia, política etc.

Diante desse cenário, as autoras Lilia Moritz Schwarcz² e Heloisa Murgel Starling ${ }^{3}$ problematizam: seria essa a primeira experiência com uma crise sanitária? Assim, recorrendo às fontes do passado, Schwarcz e Starling desenvolvem um estudo intitulado $A$ Bailarina da Morte: $A$ gripe espanhola no Brasil, publicado pela editora Companhia das Letras no ano de 2020. Conforme as autoras, a história dessa gripe, acompanhada de descobertas e de enfrentamentos sanitários, "[...] narra a saga da primeira pandemia da modernidade, a primeira grande colisão entre a natureza e a ciência moderna" (SCHWARCZ e STARLING, 2020, p.48).

A leitura e as análises empreendidas no livro nos levam a remontar o período de 1918 e 1919. Constructo dos dados encontrados em jornais e trabalhos acadêmicos, a pesquisa apresenta, além das informações acerca do surto de influenza $\mathrm{H} 1 \mathrm{~N} 1$, as possibilidades de investigação dos vários fenômenos presentes naquele fortuito período, quando a ciência havia sido relegada a um espaço de descrença e desvalorização. Outras características da leitura são as epígrafes, versos, fala de personalidades que viveram tal momento, além das fotografias, caricaturas e charges que nos aproximam de uma realidade não tão distante.

\footnotetext{
${ }^{2}$ Antropóloga e historiadora, é Professora Titular do Departamento em Antropologia Social (USP), desde 2005; Professora sênior da USP, desde 2019, e Global Scholar e Professora visitante em Princeton, desde 2011.

3 Historiadora, é Professora titular livre do Departamento de História da Universidade Federal de Minas Gerais e coordenadora da coleção Arquivos da Repressão no Brasil, pela Companhia das Letras.
} 


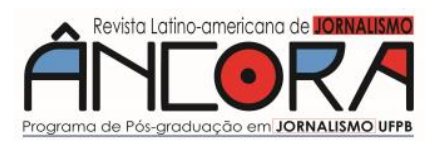

Pâmella SOUSA

As autoras demonstram, desde o início do livro, que revolver o passado - e aquele momento em especial - tem toda uma relação com as peculiaridades do campo da História. Esse revolver da e na história se apoia na ênfase aos estudos culturais os quais, ampliando a margem de documentos a serem revisitados e analisados, e sobre os quais o cientista se debruça, incluem o jornal entre as fontes pertinentes ao estudo histórico, pois que tal instrumento permite uma interface entre o registro diário de notícias e o historiador, aproximando este último do evento noticiado. Valendo-se dessa vantagem, as autoras fizeram, então, uso do jornal, além de outros artefatos. Nessa mesma direção, caminhamos teoricamente junto com Barbosa (2010) pois entendemos sua mensagem ao nos informar que, por meio do conteúdo impresso nos jornais, é possível remontar redes de diálogo.

Assim como a Covid-19, a influenza H1N1 foi um mal que veio de longe, atracando nos portos fluviais do Brasil e estendendo-se com uma larga de contaminação e mortes. Esse estranho surto atingia a sociedade em um período de morbidade econômica "[...] O moral da população andava baixo, e a doença atingia tanto a economia como a capacidade de mobilização da sociedade" (SCHWARCZ e STARLING, 2020, p.11).

$\mathrm{Na}$ introdução de $O$ mal que veio de longe, vê-se, logo de início, uma articulação entre Fernando Pessoa e uma manchete de filiação anarquista. 0 tabloide, nos informa as autoras, apresenta o cenário caótico da Grande Guerra, assoado por uma "[...]nova maneira de guerrear" (SCHWARCZ e STARLING, 2020, p.12). Entre as novas possibilidades de empreender o mal do oponente, eis que surge a gripe, uma doença esquisita, mas que, em uma média de três meses, infectou um quinto da população mundial e atingiu um patamar de mortes que ultrapassava a crueldade das armas de guerra.

Tratar da contaminação de um vírus no Brasil nos aproxima, então, da possibilidade de re/conhecer velhos problemas que caracterizam o modo político, econômico e social de desenvolvimento desta nação - é impossível 
não fazer relações do cenário social decorrido dos efeitos da Covid-19. Assim como o atual contexto que nos afeta, a influenza H1N1 surpreendeu a comunidade científica, políticos e a população. É bem verdade que, em 1918, a ciência não tinha $O$ alto nível de conhecimento que se tem hoje nem tampouco o acesso a valiosas informações como atualmente. A falta de informações acerca da grande possibilidade de mutação do vírus dificultava, sobremaneira, o reconhecimento desse processo e formas de imunização.

A contaminação da influenza H1N1 se deu ainda nos campos de batalha, porém, no esfriamento da guerra, "[...] de repente surgiu do nada outra 'arma'" (SCHWARCZ e STARLING, 2020, p.13); logo esse mal se alastraria para o mundo. As ondas de contágio tinham sempre o mesmo característico: navios com pessoas doentes, na sua maioria tripulantes da terceira classe, atracavam em diversos portos e deixavam um rastro de confusão, dor, medo e morte. O Brasil demorou a providenciar meios para inibir o contágio, como o isolamento social, por exemplo. Essa falta de atitude intensificou a contaminação da população - os pobres foram as maiores vítimas. Assim, em 1918, a gripe espanhola, patologia causada pelo vírus da influenza H1N1, não fez distinção de classe social, embora tivesse levado à morte as pessoas mais vulneráveis, as que moravam à margem da cidade mencionamos aqui os casos do Rio de Janeiro, uma cidade que se pautava pelo embelezamento das vias e onde vivia grande número de negros e pobres relegados à falta de saneamento, moradia, água e dignidade.

Além do que nos ocorre quando da leitura da Introdução, continuamos comovidos e embriagados pelo desejo contínuo da leitura do compêndio que, em dez capítulos, versa sobre a forma como foi recebida, encarada e solucionada a epidemia da gripe espanhola, até chegarmos ao capítulo da Conclusão. Durante essa leitura, verificamos a falta de consenso e coesão entre os estados brasileiros, no que diz respeito às formas como a doença foi tratada no País. Apesar disso, em um determinado instante, ela cessou, 


\section{ANIERA}

Pâmella SOUSA

embora deixando um legado de confusões e aprendizados que não podem ser esquecidos.

A espanhola chega a bordo de um navio: salve-se quem puder apresenta um panorama da chegada da doença ao Brasil. Diariamente os jornais noticiavam a quantidade de mortos e as medidas tomadas para evitar o contágio, nos Estados Unidos e na Europa. Durante algum tempo, cogitouse a morosidade da chegada do vírus ao Brasil, inicialmente pela distância e tardiamente pela recepção diferenciada que teria em um País tropical também porque "[...] Deus era brasileiro e bloquearia a entrada do inimigo invisível" (SCHWARCZ e STARLING, 2020, p. 52).

O primeiro indício de contaminações em brasileiros decorreu da Missão Médica Militar - integrantes das forças armadas enviados para Paris, em auxílio às vítimas da guerra. A bordo do navio La Plata, os militares foram os primeiros a serem noticiados como portadores da doença. Porém, o cenário brasileiro de péssimas condições logo traria a batalha do vírus para a população civil, causando uma mistura de sentimentos atordoados pela pouca informação, medo e angústia.

O navio Demerara foi apelidado de Navio da Morte, porém outras embarcações também estavam assoladas pelo vírus. Infelizmente algumas cidades foram surpreendidas não só com a falta de caixões e de coveiros pois estes haviam sido vitimados pela doença - como também pela falta de estruturas para lidar com a quantidade de enterros diários.

Em resultado da situação atordoada, somos surpreendidos com "Tanatormobia": a doença que mata no Recife -, destacando a astúcia e precisão dos repórteres do jornal $A$ Província. Esse jornal, desconfiado dos dados informados pela Diretoria de Higiene e Saúde Pública, enviava diariamente seus profissionais para a coleta de dados. E daí se lê: "[...] O jornal concluía que nunca, em Pernambuco, outra epidemia fizera tantas vítimas em tão curto espaço de tempo" (SCHWARCZ e STARLING, 2020, p.69). Mais 
alarmante, destacava o jornal, era a quantidade de enterros que não correspondia com os números divulgados pelo governo. A resposta não tardou a aparecer: noticiou-se no Jornal Pequeno a existência de uma moléstia indeterminada, designada pelas autoridades como tanatormobia. Para piorar a situação, "[...] A Diretoria de Higiene estava maquiando os registros de óbitos e apagando friamente o mapa da epidemia para atender a um propósito político" (SCHWARCZ e STARLING, 2020, p.73).

Entre o avanço contínuo da doença e as brigas políticas que faziam parte do cotidiano pernambucano, foram minimizadas as possibilidades de enfrentamento à crise. $\mathrm{O}$ vírus, entretanto, não ajudava e, à medida que avançava, demonstrava não apenas que tinha um alto grau de letalidade, mas também que sua forma de inoculação era diferente de todas as crises gripais já presenciadas. Os jornais que tiveram centralidade nas denúncias também tiveram papel importante na difusão de informações sobre os acontecimentos diversos e de meios para prevenção contra tal moléstia.

Nessa confusão sanitária, viu-se o aumento de casos de contaminação, farmácias tardando a abertura de suas portas por falta de funcionários, número insuficiente de médicos para atendimento e, consequentemente, hospitais lotados. Com a insuficiência da medicina, chegaram a ser prescritos quinino e aspirina. Um pouco mais tarde, como forma de tentar deter a doença, as receitas caseiras passaram do ambiente doméstico para as páginas dos jornais. Valia tudo para se livrar da espanhola, porém foi inevitável fugir da morbidade impregnada na cidade nos anos de 1918 e 1919.

A Escala em Salvador de Todos os Santos seguiu a inspeção de higiene, porém a vistoria percebera, tardiamente, que os infectados manifestavam a doença de diferentes formas, ainda que o fim acabasse sendo o mesmo. Após a morte de dois tripulantes do Demerara, a doença invadiu Salvador, gerando altos índices de contaminação. Apesar da propagação, a doença não foi divulgada no estado da Bahia como o fora em Pernambuco, sendo a Igreja 


\section{ÂNEORA}

Pâmella SOUSA

Católica responsável pela informação da doença bem como por identificar as medidas que deveriam ser adotadas pelos baianos para se prevenirem contra o contágio.

O esclarecimento e as medidas de segurança são necessários, aliás, indispensáveis em tempos de crise, já que a forte marca da religiosidade brasileira acaba interferindo na propagação de algumas informações associadas às práticas de curandeirismo, que infelizmente surtiam pouco ou nenhum efeito no tratamento da gripe.

Com a falta de estrutura, principalmente das localidades mais pobres, a crise de alimentos não tardou a chegar. Muitos eram os motivos para desespero, pois os preços altos dos gêneros alimentícios e a falta de trabalho fizeram companhia à crise sanitária.

Como em outros estados, $A$ espanhola invadiu a capital federal do Brasil, e o Rio de Janeiro também não estava preparado para a epidemia. No cenário da Cidade Maravilhosa, o jornal também apareceu como espaço para esclarecimentos. Inicialmente eram notas pequenas, mas, com o aumento da contaminação e abuso do setor comerciário na cobrança de custos altíssimos, o periódico $O$ Paiz desmontava as notícias duvidosas. As autoras ressaltam que atualmente vivemos um período de divulgação de muitas notícias, mais acentuado do que no passado, mas essas notas, hoje denominadas de fake news se fizeram presentes no surto da influenza H1N1 gerando também um clima de instabilidade. Muitas mortes foram registradas na capital, e, entre as grandes perdas, visualizamos a notícia de falecimento de uma criança realmente a doença não fazia distinção de quem contaminar. A comoção da situação impulsionou o fechamento das escolas. Para além das escolas, tudo estava parando, não apenas como medida de proteção, mas por falta de pessoas para operacionalizar a cidade.

O número de órfãos também aumentou; muitas crianças perderam suas famílias, e o desespero aumentava sem proporção, ocasionando mortes 
também por suicídio. Apesar da demora nas decisões das autoridades políticas e sanitárias - e até da falta delas -, um marco permaneceu forte entre os cariocas: diante de tantas tragédias, talvez a solução realmente fosse o riso. O humor empregado nas charges e caricaturas iam da confusão matrimonial a respeito de quem era a "espanhola" até as críticas pela situação vivida.

São Paulo "espanholada"nos traz muitos indícios do comportamento da população e hábitos que precisavam ser mudados, evitados. Apertar a mão, não pode! Escarrar no chão, jamais! Era preciso limpeza, pessoas saudáveis e bem alimentadas, casas varridas e tudo no seu lugar. A realidade, porém, era distinta. São Paulo crescia aceleradamente e contava com uma população em abundante multiplicação; era uma mistura de sujeitos, culturas e práticas que se articulariam na contaminação bem como na tentativa de remediá-la.

Como nos outros exemplos, o surto se iniciou nos portos, se alastrando para a cidade com rapidez. O poder público não reagia; mantinha-se omisso na tentativa de manter a calma da população. Outro viés era a culpa, afinal tudo aquilo e todos os contaminados decorreram do Rio de Janeiro. Notadamente, com o avanço da doença, foi impossível permanecer distante da situação. O Serviço Sanitário do Estado, seguindo as diretrizes de Carlos Seidl - Diretor-Geral da Saúde Pública Nacional -, emitiu comunicados que permaneciam minimizando a situação; opostamente a esses comunicados, cresciam as práticas de cura caseira, a automedicação e também a mobilização social em prol da ajuda mútua.

Belo Horizonte: a cidade que se julgava salubre, assim como outras cidades, foi atingida pela doença e tardiamente tomou medidas de prevenção; no entanto, Samuel Libânio, Diretor de Higiene de Minas Gerais, ao compreender a profusão do surto, entendeu também que seriam necessárias medidas coletivas, para enfrentamento ao vírus.

A população belo-horizontina extremamente confiante na salubridade da cidade, se comportava de maneira irresponsável. Tal situação assustava os 


\section{ANIEORA}

Pâmella SOUSA

médicos sanitaristas. Essa preocupação sanitária apontou que, diferente das outras cidades, a doença em Belo Horizonte não se tornou moeda de troca política.

Era difícil comunicar toda a população acerca dos cuidados, já que muitos não sabiam ler ou escrever e ou mantinham práticas de cuidados caseiros. Considerando tais aspectos, a alternativa encontrada pela Diretoria de Higiene foi conseguir o apoio das associações religiosas. Esse apoio foi de significante importância, pois mobilizou outras atitudes filantrópicas em prol da proteção social. Mesmo assim, a população vulnerável mantinha-se nas práticas já costumeiras de autocuidado, incentivando e intensificando a proposição de remédios que supostamente favoreceriam a cura da espanhola.

Espanhola não combina com chimarrão. Este capítulo nos mostra que as condições de salubridade e sanitarismo influenciam notadamente como cuidados principais e na medicação, fatores que ajudariam a minimizar os efeitos da influenza H1N1.

O Rio Grande do Sul foi tomado também por uma onda de falsificações de medicamentos, alimentos etc. e de uma abundância de "espertos" que procuravam vender soluções fáceis para tratamento. O chimarrão, bebida oferecida como prática social de acolhimento e hospitalidade, estava totalmente vetado, assim como visitas ou qualquer outro tipo de cumprimentos calorosos.

Os jornais evidenciavam ali, assim como nos outros estados, a situação catastrófica vivida pela população e questionavam a divergência entre 0 quantitativo real de pessoas contaminadas e o número fornecido pelo governo. A resposta foi a censura, que não tardou a ser exposta também nas caricaturas, como críticas.

Em contraponto com a modernidade auspiciosa das cidades brasileiras, as autoras também narram $A$ espanhola na terra da borracha - Belém. A Paris do Sol também tinha o seu cartão postal, o que não evitou a chegada da 
"espanhola". Tudo aconteceu de forma parecida: de início, o negacionismo associado à cultura de desvalorização do saber indígena, quando, na realidade, estavam todos expostos ao mesmo infortúnio, logo seria necessário juntar forças para vencê-lo.

Um pouco da observação do ocorrido nos outros estados deu um pequeno alívio na tentativa de prevenção. Era muito complicado estabelecer formas de tratamento para uma doença sobre a qual nada se conhecia. Assim, foram proibidos, ainda que lenta, porém, paulatinamente, todas as atividades que geravam aglomerações.

As práticas de homeopatia também tomaram as páginas dos jornais, chegando a ser recomendadas pelos médicos manauenses quando da comemoração das festas juninas, extraordinariamente em novembro, também por conta da pandemia; nessas comemorações a população prepararia fogueiras em frente de casa e o governo distribuiria ramos de alcatrão a serem queimados, acreditando que tal planta poderia ajudar no tratamento.

Estendendo-se até 1919, a gripe provocou a morte de muitas comunidades indígenas - algumas chegaram a ser parcialmente dizimadas. $\mathrm{E}$ em meio a tanta dor, em março de 1919, a doença precisou ceder espaço para preparar o carnaval. Assim como chegou, a espanhola foi embora, repentinamente.

Por fim, mas não menos importante, Quem matou Rodrigues A/ves? Em janeiro de 1919, é solenemente enterrado o Presidente do Brasil. Transitando entre o mistério da causa da sua morte e o ritual do enterro, os jornais assumem novamente o espaço de tecer a história ora apresentada. As autoras atentam para o ritual empreendido na República, categorizando o vulto social enquanto expressão de patriotismo. Para além dessas questões, no entanto, pairavam as dúvidas acerca da causa da morte do Presidente. Afinal, o espectro da espanhola ainda estava muito próximo da população. Fantasma 


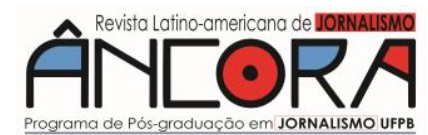

Pâmella SOUSA

que não impediu a aglomeração no cortejo, como nos mostra o registro do funeral identificado pelas autoras.

Assim, No tempo da espanhola, percebe-se que muitas vítimas, embora não tenham seu nome conhecido ou divulgado, deixaram um rastro de dor. As considerações do texto são apanhadas de análises de fotografias, parte do acervo fotográfico da Fundação Oswaldo Cruz, as quais poderemos visualizar ao longo das páginas desse livro. Esse registro nos mostra a cor e o rosto dos maiores afetados por essa crise sanitária. Para além de todas as informações já mencionadas, registrar nossas atitudes num contexto tão desesperador se torna ato fundamental, contribuindo para o ensinamento de todos.

Em todas as cidades foi altíssima a quantidade de mortos, e em todas as situações percebemos a falta de uma orientação coletiva acerca do tratamento da doença. Muitos se preocupavam em culpar o outro pela contaminação e não davam a devida importância à amplitude do problema que se encontrava ao lado. A meu ver, as autoras nos sensibilizam enquanto sujeitos vulneráveis, mas principalmente enquanto pessoas com capacidade de se adaptar, reinventar, narrar e não deixar de registrar esse momento que, apesar de temeroso, foi de crescimento para a população. É notório que não devemos silenciar, que o acontecido no surto da influenza H1N1 e o que está acontecendo com a pandemia da Covid-19 precisa ser comunicado, e, assim como no século passado, a imprensa tem papel informativo e denunciativo nesse cenário.

Vale dizer que a cultura local foi um forte influenciador em relação à forma como a doença foi recebida pela população. A medicina, ensaiando seus primeiros passos em direção ao enfrentamento de um vírus desconhecido, e o cenário caótico da guerra influenciaram bastante no modus operandi de tratamento da doença.

O livro deixa claro que somos um todo, que são necessários, sim, cuidados individuais, mas que as atitudes repercutem de forma geral. Assim 
como em 1918, o brasileiro de 2020/21 se mostrou uma pessoa capaz de ajudar o outro nas adversidades, de criar mecanismos de doação e também do sorriso improvisado.

Os jornais tiveram, naquele período, centralidade na divulgação das notícias, serviam para comunicar, denunciar, informar e foram o registro de grande valia para esse momento de questionamento. Embora existissem notícias falsas, tentativa de aproveitamento da sensibilidade, é impossível negar que práticas foram mudadas e que chegaram até os nossos dias sem remeter especificamente ao vírus da influenza H1N1. Alguns dos cuidados recomendados já ou ainda fazem partem, inclusive, do nosso cotidiano.

Negar a doença em 1918, tanto por parte do corpo político do País como da população, nos remete a pensar o atual cenário. O negacionismo de outrora muito tinha a ver com a escassez de informações e desconhecimento da ciência. Situações que parecem se repetir e que apontam para o fato de que a modernidade preconizada para o século XXI talvez esbarre na compreensão de que o século $X X$ ainda está por findar.

A Bailarina da Morte: A gripe espanhola no Brasilé um ótimo exercício de reflexão e conhecimento da nossa história. A problematização é muito atual e nos faz indagar: Como podemos repetir erros tão comuns em tão curto espaço de tempo? A resposta pode vir da análise, do conhecer, do refletir, mas, sem dúvida nenhuma, culminará na falta de atitude de muitos e de todos.

\section{Referências}

BARBOSA, Marialva. História cultural da imprensa: Brasil - 1800-1900. Rio de Janeiro: Mauad X, 2010.

SCHWARCZ, Lilia Moritz. STARLING, Heloisa Murgel. A Bailarina da Morte: a gripe espanhola no Brasil. $1^{\text {a }}$ ed. - São Paulo: Companhia das Letras, 2020. 375 p. 